\title{
Morte no cartão postal: uma empresa, dois jornais e três vítimas
}

\section{Death in a postcard: one company, two newspapers, three victims}

Márcia Franz Amaral ${ }^{1}$

Lara Nasi ${ }^{2}$

Resumo: Analisamos as configurações da violência urbana nas narrativas jornalísticas de dois jornais da Infoglobo (O Globo e Extra) a partir da análise de capas e matérias sobre um caso de latrocínio de grande repercussão midiática. Investigamos como os personagens de vítima e de agressor compõem cada narrativa, relacionando-os às noções de "política da piedade" e "vítima virtual". Concluímos que estão em jogo nesse enredo vítimas de várias ordens: fatais, sociais e virtuais. O estudo evidencia como, para além do "fato em bruto", as narrativas jornalísticas podem configurar um acontecimento de maneiras diferentes, já que os jornais precisam se individualizar no mercado editorial e, portanto, oferecem leituras diversas para a experiência social da violência de acordo com projetos dramáticos diferentes.

Palavras-chave: jornalismo; narrativa; violência; criminalidade.

Abstract: In this essay, we analyze the narrative configuration of urban violence in two newspapers of the same editorial group (O Globo e Extra, both from Infoglobo), from the covers and stories published about an armed robbery that had a strong mass media repercussion. We study how the characters of victim and aggressor compose each narrative, relating them to the notions of politics of pity and virtual victim. We conclude that victims of different orders are in

1 Universidade Federal de Santa Maria. Santa Maria, RS, Brasil. https://orcid.org/0000-0001-7283-474X E-mail: marciafranz.amaral@gmail.com

2 Universidade Federal de Santa Maria. Santa Maria, RS, Brasil.

https://orcid.org/0000-0002-9055-5135 E-mail: nasi.lara@gmail.com 
question: fatal, social and virtual. The study highlights how, beyond the "raw fact", journalistic narrative can configure an event in different ways, since the newspapers need to individualize themselves in the editorial market and, therefore, give several intelligibilities to the social experience of violence, according to different dramatic projects.

Keywords: journalism; narrative; violence; crime. 


\section{Considerações iniciais}

Dia 19 de maio de 2015. Em meio à retomada da discussão da redução da maioridade penal no Brasil por parte do Congresso Nacional, um médico é abordado e agredido a facadas por dois adolescentes no Rio de Janeiro enquanto pedalava no entorno da lagoa Rodrigo de Freitas. Sua bicicleta e carteira são levadas. Atendido em um hospital nas proximidades, o médico não resiste e morre na manhã do dia 20 de maio, quando os jornais daquele dia já circulam na cidade. No mesmo dia, um dos suspeitos é identificado pela polícia. É morador da favela de Manguinhos e tem 16 anos.

O acontecimento assume lugar importante nos noticiários em diferentes mídias e é o fio condutor para uma discussão que envolve, além da morte do médico, a redução da maioridade penal, a proibição do porte de arma branca, o aumento da pena nos casos de roubo ou furto de bicicleta, a vulnerabilidade de quem anda nas ruas e a vida pregressa dos adolescentes infratores.

Enquanto o jornal O Globo publica a chamada de capa "Na lagoa, mais um esfaqueado" (O Globo, 20 maio 2015, p. 1), o Extra, jornal do mesmo grupo editorial, traz em sua primeira página a manchete "Crime bárbaro na Lagoa choca Rio", com o texto: "Só não se esqueçam de Gilson e Vanderson" (Extra, 21 maio 2015, p. 1). O caso diz respeito a um adolescente e um jovem mortos pela polícia em uma operação policial no morro do Dendê. A capa apresenta também a discussão: "Como em qualquer lugar do mundo, crimes em pontos turísticos têm maior repercussão. Mas, no Dendê, mães choram morte de seus filhos em ação da polícia e esperam que caso não caia no esquecimento" (Extra, 21 maio 2015, p. 1). No dia seguinte, 22, o Extra aborda o assassinato do médico com a manchete "Duas tragédias antes da tragédia. Sem família, sem escola" (Extra, 22 maio 2015, p. 1), referindo-se à vida pregressa do acusado.

Nosso objetivo é refletir sobre as diferentes possibilidades de configuração desse tipo de acontecimento pela narrativa jornalística, especialmente no que tange à construção do crime e dos personagens. Tomamos por base uma pesquisa realizada por Vaz e colaboradores 
(2005 e 2006) sobre o jornal O Globo que investigou os modos como o jornalismo narra o crime e constrói a ideia de sofrimento entre os anos de 1983 e $2001 .{ }^{3}$ Analisamos como esse tipo de narrativa ${ }^{4}$ é configurado anos depois, motivado tanto pelo debate sobre a redução da maioridade penal que circundava a discussão sobre o crime em questão quanto pela polêmica que esse acontecimento e sua cobertura por dois jornais do Grupo Globo geraram também nas mídias sociais.

Dedicamos a análise aos primeiros dois dias da cobertura (20 matérias e quatro capas dos dias 21 e 22 de maio de 2015) nos jornais O Globo e Extra. Metodologicamente, elaboramos um protocolo de análise que destaca as sequências narrativas relativas à descrição do crime, da vítima e dos agressores para fazer um cotejamento entre as narrativas. O propósito é perceber como os jornais constroem a relação vítima-agressor-leitor e quais são as formas de identificação que as publicações oferecem aos seus leitores com base em diferentes configurações do acontecimento.

\section{Modos de narrar o crime, os agressores e as vítimas}

De nosso ponto de vista, a narrativa é um "dispositivo de argumentação na relação entre sujeitos" (MOTTA, 2005, p. 4) e o narrador "investe na organização narrativa do seu discurso e solicita uma determinada interpretação por parte do seu destinatário" (MOTTA, 2005, p. 3). Um dos movimentos de análise importantes no estudo das narrativas é compreender o "projeto dramático" do narrador: "Quem narra tem sempre algum propósito: nenhuma narrativa é ingênua, neutra, imparcial; toda narrativa é argumentativa. Quer atrair, seduzir, envolver, convencer, provocar efeitos de sentido" (MOTTA, 2013, p. 196).

Para mostrar como os modos de narrar a violência urbana se modificam ao longo da história, partimos de Vaz, Carvalho e Pombo (2006),

3 Consideramos importante retomar pesquisas já realizadas tendo em vista que a produção científica tem um caráter cumulativo e coletivo e que a ordem de problemas que se apresentam nesse artigo pode ficar mais clara se for percebida não apenas na sua configuração nesse caso, mas também ao longo do tempo.

4 Embora Vaz e colaboradores $(2005,2006)$ não utilizem a perspectiva da narrativa, tomada como base neste trabalho, trazem importantes aportes para o tema da cobertura da violência urbana. 
que analisaram as mudanças na imagem do criminoso no noticiário de crime do jornal O Globo entre os anos de 1983 e 2001. Na década de 1980, em notícias sobre crimes de proximidade cometidos por pessoas da família, amigo ou namorado, os autores observam que o texto jornalístico era conduzido do ponto de vista do agressor, que acabava tendo voz nas matérias: "[...] há uma comum humanidade entre o criminoso e a audiência” (VAZ, CARVALHO e POMBO, 2006, p. 77). Dizem os autores que havia "uma identificação primária com o criminoso, só que não mais no plano afetivo, e sim por pensar que, se estivesse no seu lugar, poderia fazer o mesmo”, ou seja, "o crime ganha dimensão política e a forma de evitá-lo é criar melhores condições sociais [...]” (VAZ, CARVALHO e POMBO, 2006, p. 77). Nos anos 2000, entretanto, o crime passa a ser narrado de outro ponto de vista: o jornal começa a trazer as declarações das vítimas e parentes e a dor e revolta "passam a ser representativas da experiência de todos os leitores” (VAZ, CARVALHO e POMBO, 2006, p. 78). Há um crescente desinteresse pelos crimes de proximidade e maior visibilidade dos crimes cometidos por estranhos no espaço público e com vítimas aleatórias, "isto é, crimes que generalizam a possibilidade de vitimização” (VAZ, CARVALHO e POMBO, 2006, p. 75). Nesse processo, não há mais identificação possível entre a audiência e o criminoso, optando-se por privilegiar o ponto de vista da vítima:

A partir dessa forma de aparecimento do sofrimento do crime na mídia, o que se solidifica é o sofrimento evitável tal como é concebido pelo populismo conservador: se houvesse mais polícia, se as leis fossem mais rigorosas e se as prisões contivessem os prisioneiros, o sofrimento seria evitado (VAZ, CARVALHO e POMBO, 2006, p. 75).

A partir desse estudo, vários trabalhos (VAZ, CARVALHO e POMBO, 2005, 2006; VAZ e RONY, 201 1; VAZ, CARDOSO e FELIX, 2012; VAZ, 2014) refletem sobre como o sofrimento tem visibilidade na mídia e buscam sistematizar suas configurações em, pelo menos, duas perspectivas, da "política da piedade" e da "vítima virtual", às quais nos dedicamos a seguir, estudando O Globo e o Extra nessa cobertura de 2015. 
É em Arendt (1988) e Boltanksi (2004) que Vaz e colaboradores (2006) buscam aportes para trabalhar com a política da piedade, ideia que emergiu com a Revolução Francesa. Para definir o que seria piedade, Arendt (1988) a diferencia de compaixão. Esta seria "ser atingido pelo sofrimento alheio, como se fosse algo de contagioso" e aquela, "sentir sem ser tocado na carne" (ARENDT, 1988, p. 67). A compaixão, explica a autora, não pode ir além do que é sofrido por uma pessoa e se estender a uma classe, a um povo ou à humanidade como um todo; ela seria um "cossofrimento", portanto, sua força estaria no particular, movida pela paixão (ARENDT, 1988, p. 68). Já na piedade, se despersonalizam os sofredores, englobando-os, de modo que se possa falar em "massas sofredoras", por exemplo. "A piedade, por não ser atingida na carne, e conservar sua distância sentimental, pode ser bem-sucedida onde a compaixão costuma fracassar; ela pode alcançar a multidão e, por conseguinte, como a solidariedade, entrar em praça pública" (ARENDT, 1988, p. 71). A piedade, explica a autora, só existe na presença do infortúnio, necessita da existência dos infelizes e, por isso, se diferencia da solidariedade.

Boltanski (2004), a partir da leitura de Arendt, caracteriza a política da piedade na distinção entre os que sofrem e os que não sofrem e por haver um foco no que é visto, no "espetáculo do sofrimento". O autor entende que, na formulação de Arendt, esse sofrimento não está centrado na ação, no poder do forte sobre o fraco, mas na observação dos desafortunados por aqueles que não compartilham de seu sofrimento, não o experimentam diretamente e que, por isso, podem ser considerados afortunados (BOLTANSKI, 2004, p. 3). Com isso, a política da piedade se distancia da ideia de justiça. "Para uma política da piedade, a urgência da ação para dar fim ao sofrimento sempre prevalece sobre a justiça. Nessa perspectiva, somente em um mundo no qual o sofrimento tenha sido banido a justiça pode fazer cumprir seus direitos" (BOLTANSKI, 2004, p. 4, tradução nossa). ${ }^{5}$

5 No original: "For a politics of pity, the urgency of the action needing to be taken to bring an end to the suffering invoked always prevails over considerations of justice. From such a perspective it is only in a world from which suffering has been banished that justice could enforce its rights". 
Na leitura de Vaz e colaboradores (2006), a política da piedade define a estrutura básica da solidariedade em uma sociedade complexa ao colocar em relação, à distância, observador e sofredor desconhecidos. Essa leitura pode ser feita para o que se via nos jornais, por exemplo, na década de 1980. "O sofredor não é conhecido, nem a ajuda pode ser local; ela deve se dar na forma de uma palavra pública dirigida a outros não sofredores, convidando-os a se mobilizarem para evitar ou reduzir esse sofrimento" (VAZ et al., 2006, p. 114). Dessa forma, "uma notícia sobre um crime podia também ser um modo de gerar indignação contra o sistema” (VAZ et al., 2006, p. 114).

Os autores observam que quando havia esse deslocamento e a associação do crime ao contexto social, eram baixas as taxas de criminalidade. Mas, à medida que aumenta sua incidência, os atos criminosos ganham caráter cada vez maior de aleatoriedade e de danos físicos (VAZ et al., 2006).

Há, então, uma passagem da piedade ao que os autores conceituam como política da vítima virtual, referindo-se a uma política do medo contemporânea. Enquanto na política da piedade a "audiência é construída como os felizes, à diferença do sofredor, e responsável pelo sofrimento deste, nem que seja por nada fazer quando poderia" (VAZ, CARDOSO e FELIX, 2012, p. 29), na política da vítima virtual, "a audiência é estimulada a se conceber na mesma condição daquele que sofre, o que desloca a busca da responsabilidade pelo sofrimento para um personagem outro" (VAZ, CARDOSO e FELIX, 2012, p. 29). Essa passagem se concretiza "pela emergência da Vítima Virtual como figura subjetiva e política característica da nossa atualidade, bem como pelo predomínio de um novo ideal de justiça social: o direito à rotina segura e feliz" (VAZ, CARDOSO e FELIX, 2012, p. 30).

$\mathrm{Na}$ política da vítima virtual, destacam-se as narrativas singulares: "não mais eventos vinculados à estrutura social, mas acontecimentos que ocorrem no espaço público com seleção aleatória de vítimas: crimes, catástrofes naturais, epidemias e acidentes" (VAZ, CARDOSO e FELIX, 2012, p. 35). Além disso, os sofredores não são mais despersonalizados: agora, há um interesse na singularidade de suas histórias, em sua 
felicidade até aquele momento. Entretanto, a "individualização [...] é uma forma de generalização” (VAZ, CARDOSO e FELIX, 2012, p. 36).

\section{Um crime, dois jornais e várias vítimas}

Partimos para a análise do caso do latrocínio que envolveu o médico Jaime Gold para mobilizar as reflexões trazidas pelos estudos citados.

\section{A descrição da cobertura}

A primeira notícia da morte de Jaime Gold não nomeia o médico. Em O Globo, é publicada na edição de 20 de maio de 2015 com a chamada de capa "Na lagoa, mais um esfaqueado". A notícia, na página 13, mostra a foto da vítima não identificada, de capacete e trajes de ciclismo, ensanguentada, sendo socorrida. Ao longo daquele dia, a família e os amigos fazem publicações consternadas nas mídias sociais, levando autoridades como o secretário de Segurança do Rio, José Mariano Beltrame, a também se pronunciar sobre o assunto nas mesmas mídias.

No dia seguinte, 21, o leitor encontra no jornal O Globo seis páginas dedicadas ao tema. Na capa (Figura 1), a manchete: "Tragédia anunciada choca Rio" (O Globo, 21 maio 2015, p. 1). A edição apresenta uma matéria de página inteira com o perfil do médico, lamentando sua morte. O texto resgata a indignação nas mídias sociais, repercute a mudança de rotina dos frequentadores da Lagoa para evitar assaltos, ressalta a insegurança em um cartão-postal da cidade e observa que, na região, o número de jovens detidos é maior que o de adultos.

No dia 22, o assunto continua em pauta no jornal. Dessa vez, destacando o fato de um dos suspeitos ter sido encontrado e detido pela polícia. São quatro matérias e um editorial. A matéria anunciada na capa (Figura 2) observa a detenção de um menino com longo histórico de passagens pela polícia; na mesma edição, a divisão de opiniões com relação à redução da maioridade penal é abordada sob a cartola "Luto na Lagoa”, que ainda abriga matérias sobre o enterro do médico assassinado, a comoção de familiares e amigos e o anúncio feito pela Polícia 
Militar de que vai implantar patrulhamento especial em áreas de lazer. O editorial, intitulado "Crime reforça pressão por nova maioridade penal”, critica duramente o fato de a pena para homicídios causados por adolescentes ser tão branda, citando o caso da Lagoa.

Figura 1 - Recorte da capa de O Globo de 21 de maio de 2015.

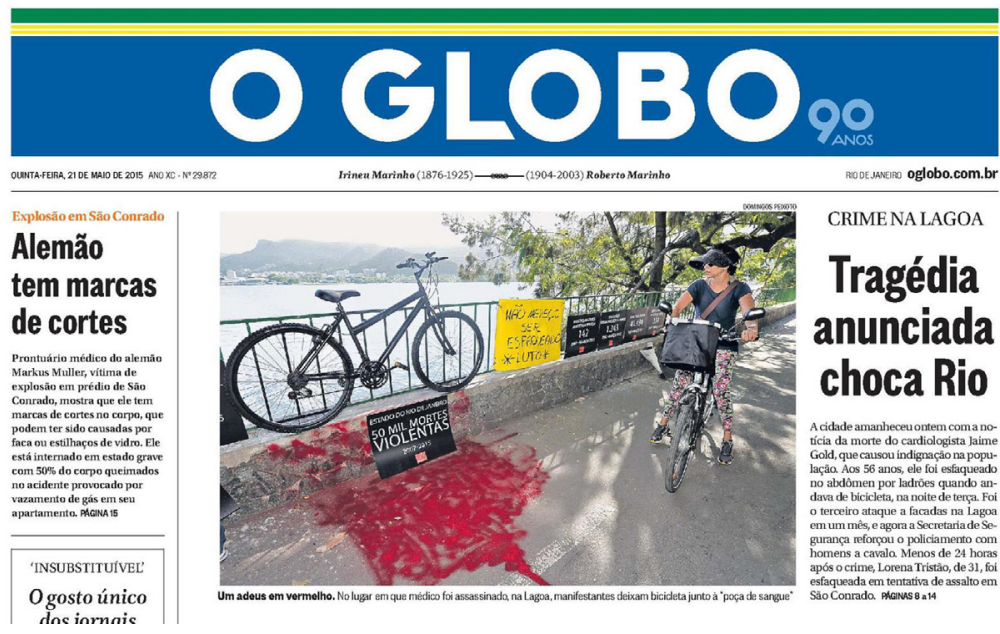

Figura 2 - Recorte da capa de O Globo de 22 de maio de 2015.

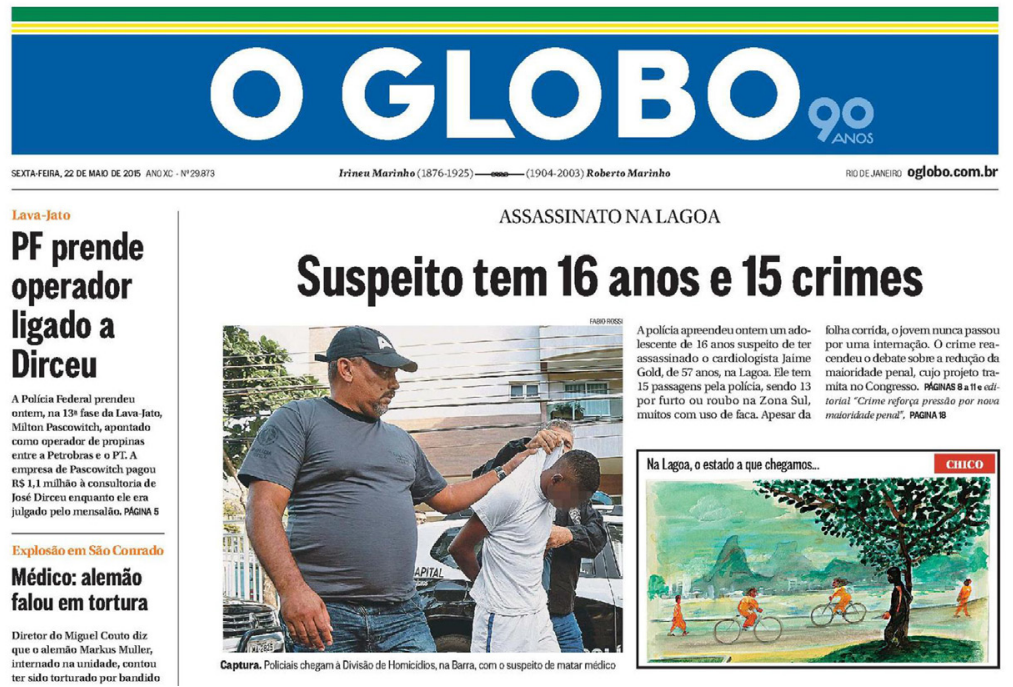


No dia 22, o Extra traz a capa "Duas tragédias antes da tragédia. Sem família, sem escola” (Figura 3). A foto é a mesma usada pelo jornal $O$ Globo quando noticia que suspeito "tem 16 anos e 15 crimes", mas a construção narrativa do Extra, ao mesmo tempo que informa sobre os atos infracionais cometidos pelo suspeito, toma outra direção. À chamada, segue o texto:

A repórter Carolina Heringer reconstituiu a vida do menor suspeito de matar o médico Jaime Gold, na Lagoa. Com 16 anos, acumula 15 passagens pela polícia, a primeira quando tinha 11 anos. O pai, ele só viu duas vezes. A mãe, catadora de latas, foi indiciada por abandoná-lo com fome na rua. A outra barreira de proteção ao menor também falhou: ele desistiu dos estudos no $6^{\circ}$ ano. E a recíproca foi verdadeira: a escola também desistiu dele. Na terça-feira, um inocente pagou com a vida pela sucessão de tragédias (Extra, 22 maio 2015, p. 1).

Figura 3 - Recorte da capa do Extra de 22 de maio de 2015.
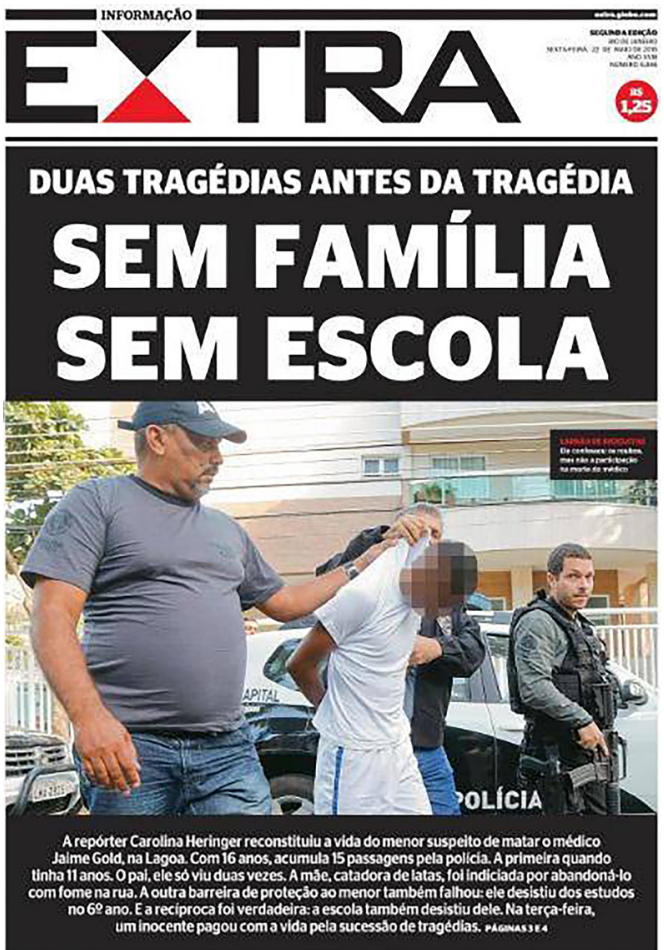
As diferenças entre as abordagens dos jornais, pertencentes ao mesmo grupo editorial, são nítidas. Tomamos por base, a seguir, as sequências narrativas que relatam o crime, o local, a vítima e os criminosos nos dois jornais.

\section{Descrição da cena do crime}

Os jornais não se diferenciam na maneira de descrever o crime estrito. Entretanto, O Globo acrescenta alguns julgamentos de valor: "Escalada da crueldade - jovem de 16 anos suspeito de matar médico tem 15 passagens na polícia por roubo" (O Globo, 22 maio 2015, p. 8).

A descrição dos locais dos crimes também é similar entre as duas publicações. Ambos caracterizam a Lagoa como um "cartão-postal". Entretanto, O Globo, a partir de uma fonte, publica uma crítica que relaciona moradores de rua à escalada de violência: "Perto do heliponto, moradores de rua lavam roupas, tomam banho e fazer churrasco - lamentou o presidente da Associação de Moradores do Jardim Botânico" (O Globo, 21 maio 2015, p. 11).

O Extra, por sua vez, alerta que os crimes em locais turísticos ganham mais destaque jornalístico, mas reafirma que isso não deve nos fazer esquecer de crimes que ocorrem, por exemplo, na favela, como aponta o texto de capa da edição de 21 de maio (Figura 4).

\section{A descrição da vítima e dos agressores}

Para descrevermos as vítimas nas narrativas jornalísticas, a primeira reflexão a ser feita é sobre quem os jornais elegem para esse papel. Conforme Vaz (2014), para que se possa ter compaixão, são necessárias algumas crenças sobre quem é a vítima. Em primeiro lugar, precisamos reconhecer que o sofrimento do outro é grave, o que só é possível quando acreditamos que o sofredor é um igual. Quando ao sofredor é atribuída inferioridade ou diferença moral, ele dificilmente será digno de compaixão. A segunda crença trazida pelo autor, o "juízo sobre a inocência do sofredor” (VAZ, 2014, p.86), está relacionada à noção de que aquele 
Figura 4 - Recorte da capa do Extra de 21 de maio de 2015.

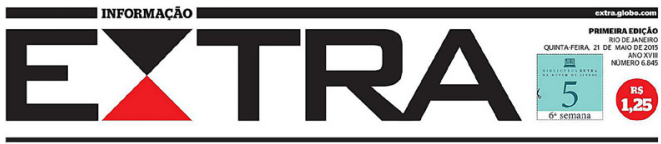

\section{CRIME BARBARO NA LAGOA CHOCA O RIO}

Morte de médico causa comoçâo erevolta nas redes sociais. Beltrame manifesta inclignaçăo,
reforça a segurança na regiấo, com policiais a cavalo, e pedeapoio à Guarda Municipal

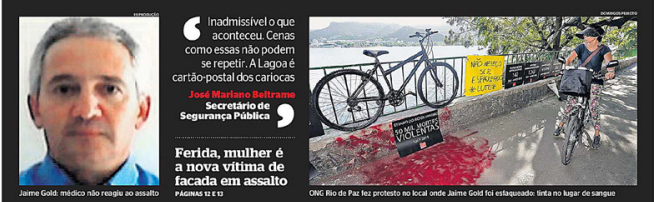

\section{SÓ NÄO SE ESQUECAM DE GILSON E WANDERSON}

Como em qualquer lugar do mundo, crimes em pontos turisticostêm maior repercussão. Mas, no Dendê,
mấes choram mortes deseus fil hos em açáo da policia e esperam que caso năo caia no esquecimento.

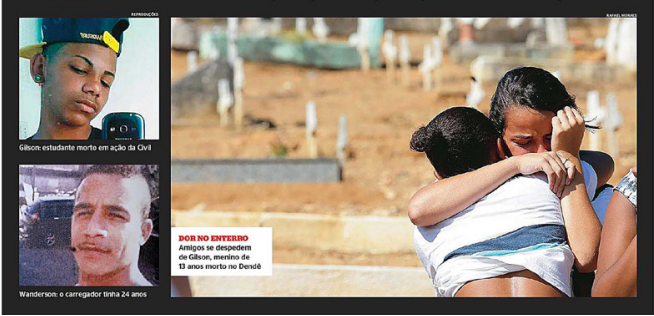

sofrimento não é merecido. No caso em análise, o médico Jaime Gold é comprovadamente inocente e detalhes sobre suas virtudes morais são exaltados em toda a cobertura de O Globo. Já o adolescente que o matou não é um sofredor para $O$ Globo, pois não é inocente e, portanto, não é digno de compaixão.

A cobertura do Extra reconhece também a inocência da vítima (o médico), embora em raras linhas: "um médico" (Extra, 21 maio 2015, p. 12), um "inocente que pagou com a vida pela sucessão de tragédias" (Extra, 22 maio 2015, p. 1). Ressalta-se nessa última frase a "sucessão de tragédias". Ou seja, abre-se um espaço para considerar também o adolescente uma vítima, embora uma vítima social. No caso da matéria sobre os adolescentes Gilson e Vanderson, mortos pela polícia, o Extra elege como vítimas também os jovens pobres assassinados no mesmo 
dia que o médico e publica a fala de uma das mães: "Meu filho não era bandido, $[. .$.$] ele era estudante - disse Eliane, mostrando o boletim do$ garoto [...]" (Extra, 21 maio 2015, p. 13).

N'O Globo, na primeira matéria das oito que compõem a coletânea sob a cartola "Luto na Lagoa", no primeiro dia de cobertura, a foto de perfil do médico ganha um recorte nos contornos de seu corpo, com uma grande ampliação, sorrindo. Há depoimentos com declarações sobre o médico do porteiro do prédio, da ex-mulher e de ator de televisão. O início do texto dá o tom de como será conduzida a narrativa:

Como diziam os mais antigos, ele não era deste mundo. Cardiologista renomado, abriu mão de consultório para se dedicar à medicina pública no Hospital do Fundão. Divorciado, virou "pãe", assumindo a criação dos dois filhos, hoje adultos. Era atleta por paixão e, quando passava pela portaria do seu prédio, sempre cumprimentava o porteiro, quando não se estendia em dois dedos de prosa. O médico Jaime Gold, de 55 anos, se despediu da vida de uma forma que não fazia jus à sua história (O Globo, 21 maio 2015 , p. 8).

A seguir, outras sequências mostram como a inocência do médico foi exaustivamente exaltada por O Globo: "Adeus, doutor", "jeito de bom moço", "disciplina espartana e porte atlético", "pessoa dedicada", "médico 24 horas por dia", "distribuía doces para animar os plantões" $(O$ Globo, 21 maio 2015, p. 8), "personalidade pacífica”, "perdemos um ser humano que só pensava no bem das pessoas", "era um menino de ouro" (O Globo, 22 maio 2015, p. 10).

A terceira crença apontada por Vaz (2014, p. 86) para que se possa ter compaixão é o "juízo de possibilidades similares”. Para o autor, na compaixão pós-moderna, se reduz "ao máximo a distância entre sofredor e audiência” (VAZ, 2014, p. 94). O leitor precisa poder se colocar no lugar do que sofre. Eventos semelhantes podem acontecer a qualquer um e em qualquer momento e o risco é generalizado. Esse “juízo de possibilidades similares" é fartamente utilizado por O Globo, que cita recorrentemente a urgência da prevenção e de recrudescimento das leis. O crime é visto como incompreensível. Há o realce da inocência e o 
aumento da indignação. Constrói-se uma comunidade imaginada de vítimas virtuais, conforme exemplificado a seguir: "[...] caminhar ou andar de bicicleta pela Lagoa tem despertado outro tipo de sentimento nos cariocas: medo" (O Globo, 21 maio 2015, p. 11). Estão presentes, no texto jornalístico, estranhos que se solidarizam com a vítima: "Mesmo sem conhecer o médico, o ciclista Mário Luiz Vides [...] saiu de São Gonçalo para prestar solidariedade à família [...]" (O Globo, 22 maio 2015, p. 10); "Estudante de psicologia e ciclista, Alexandre Rodrigues [...] afixou um cartaz com um protesto: "não mereço ser esfaqueado" (O Globo, 21 maio 2015, p. 10). Alguns grupos são nomeados como vítimas em potencial: "A morte do médico [...] espalhou indignação, medo e um sentimento de impotência entre amigos, familiares e os muitos frequentadores da área - um dos espaços de lazer mais valorizados da cidade e cenário de provas dos Jogos [Olímpicos] de 2016" (O Globo, 21 maio 2015, p. 10).

Nessa política da vítima virtual, a necessidade de punição ganha destaque. Para o jornal, os adolescentes envolvidos não são vítimas e deveriam ser punidos mais duramente. O Globo publica uma matéria, no dia 21 de maio, intitulada "Na região, número de jovens detidos é maior que o de adultos". Na mesma página, outra notícia recebe o título "Maioridade penal em discussão". Abaixo, dois artigos compõem a página, um contrário e outro favorável à redução da maioridade penal. Na capa do dia seguinte, lê-se: "O crime reacendeu o debate sobre a redução da maioridade penal, cujo projeto tramita no Congresso" (O Globo, 22 maio 2015, p. 1). No interior do jornal, nesse mesmo dia, um infográfico com um mapa indica os diversos locais em que o jovem já teria abordado outras pessoas na Lagoa. N’O Globo, várias matérias ratificam o fato de o agressor ser um adolescente, designação importante naquele momento de debate, como nos exemplos a seguir: "[...] três adolescentes foram presos ontem na Lagoa” (O Globo, 21 maio 2015, p. 10). Números da criminalidade são associados à faixa etária: "O número de adolescentes detidos em abril na área do $23^{\circ} \mathrm{BPM}$ Leblon, que compreende a Lagoa, foi maior que o de adultos presos" (O Globo, 22 maio 
2015, p. 14) e "No mês, 40 jovens foram apreendidos na região em flagrante pelos crimes de roubo e tráfico, contra 30 adultos levados para a cadeia. Ou seja, eles representaram 57\% do total de 70 casos" (O Globo, 22 maio 2015, p. 14). A relação dos números com a votação do projeto de redução da maioridade penal fica explícita na fala do governador do Rio de Janeiro, Luiz Fernando Pezão, fonte ouvida por O Globo:

- Eu não quero que a gente fique enxugando gelo. A maioria das apreensões que fazemos é de menores. É inaceitável. Lugar de menor é na escola - disse. - Só quero que seja feita uma discussão no Congresso Nacional. A polícia bateu recorde de apreensões de menores e não está sendo suficiente (O Globo, 22 maio 2015, p. 8).

No Extra, o fato de o agressor ser adolescente aparece apenas em dois trechos: "[...] um menor de 16 anos, que tem 15 anotações criminais, participou da morte do médico" (Extra, 22 maio 2015, p. 4) e "Estamos certos de que o adolescente participou efetivamente da morte" (Extra, 22 maio 2015, p. 4).

No que Vaz (2014) denomina política da piedade, há uma articulação entre sofrimento e política, ou seja, há a inclusão do sistema, fazendo com que o criminoso também seja vítima. Essa perspectiva se baseia na ideia de que todos os seres humanos nascem iguais e é injusto que alguns sofram. Os agressores são vítimas da miséria e a audiência, "superior", deveria agir politicamente contra essa situação. O Globo menciona apenas uma frase nesse sentido, nas últimas linhas de uma matéria, a partir de uma fonte, a ex-esposa do médico assassinado: "São gerações de vítimas do nosso sistema, da nossa falta de educação, de saúde" (O Globo, 21 maio 2015, p. 8). Já no Extra, essa noção perpassa várias matérias sobre o caso em questão, como na capa do dia 22 de maio: "Menor suspeito de morte na Lagoa deixou a escola aos 14 anos, só viu o pai duas vezes e era negligenciado pela mãe" (Extra, 22 maio 2015, p. 1). No interior da edição, essa perspectiva segue sendo trabalhada:

Desde 2010, foram 15 passagens pela polícia - por crimes como roubo, furto, desacato e tráfico - e nove pelo Departamento de Ações 
Socioeducativas (Degase). Por outras três vezes, X. passou pela $14^{a}$ DP, mas como vítima. [...] os policiais registraram as ocorrências como abandono material (duas vezes) e abandono de incapaz. Num dos registros, de 25 de outubro de 2010, os policiais afirmam que X. e outro menor estavam passando fome, sem dinheiro para voltar para casa (Extra, 22 maio 2015, p. 3).

A descrição dos agressores, portanto, é bem diferente nos dois jornais. N'O Globo, uma matéria relata cada um dos assaltos cometidos pelo adolescente com o uso de faca e enfatiza que ele ficou pouco tempo em internação em regime fechado. O jornal cita brevemente que ele foi torturado por agentes num crime denunciado pelo Ministério Público, mas a ênfase é na frieza do matador no caso em questão, como no trecho a seguir, creditado pelo jornal ao delegado que cuidava do caso: "A frieza do adolescente infrator e a forma covarde com que ele agiu me chamou a atenção. Ele não demonstra nenhum sentimento pelo outro ser humano" (O Globo, 22 maio 2015, p. 8). O texto jornalístico também assume essa perspectiva:

[...] antes mesmo de anunciar o roubo, o golpeou pelas costas de forma brutal. Ao ver a vítima no chão, o suspeito, ainda de acordo com a testemunha, voltou a golpeá-la, rasgando seu abdômen num longo e profundo corte de baixo para cima, que atingiu quatro órgãos e tirou de Jaime qualquer chance de sobreviver ao ataque [...] (O Globo, 22 maio 2015, p. 8).

Na mesma matéria, uma fonte é convocada para explicar o que levaria o autor a cometer o ato infracional: "Para o psicanalista Luiz Alberto Py, o autor das facadas tem traços de psicopatia: [...] 'Não conheço o rapaz $[. .$.$] . Dá a impressão de que havia um desejo de esfaquear anterior$ ao contato com a vítima, de ter prazer com isso"” (O Globo, 22 maio 2015, p. 8).

No Extra, em contraposição, o agressor ganha características que permitem que ele também seja tratado como vítima; há riqueza de detalhes sobre sua vida. Essa lógica é visível na manchete de capa "Duas tragédias antes da tragédia. Sem família, sem escola”, do dia 22 de maio, bem como nos trechos a seguir: "Garoto suspeito de matar médico tem 
histórico de fome, evasão escolar e abandono" (Extra, 22 maio 2015, p. 3) e "Ele confessou os roubos, mas não a participação na morte do médico" (Extra, 22 maio 2015, p. 4).

As diferentes construções desses personagens indicam projetos dramáticos diversos que buscam criar efeitos de sentido também diferenciados em cada nicho de leitores. Embora não se possa assegurar que as estratégias dos jornais de fato tenham sucesso, faz-se necessário afirmar que se trata de estratégias organizadoras dos discursos que convocam também o leitor a ocupar posições diferentes e a compreender o crime em configurações muito diversas.

\section{O criminoso, a vítima e o leitor: triangulações possíveis}

Os dois jornais integram o mesmo grupo editorial, as Organizações Globo, em seu braço dedicado às publicações jornalísticas impressas, a Infoglobo. O Globo, primeira mídia informativa do grupo, está em circulação desde 1925; já o Extra surge sete décadas depois, em 1998. A proposta era produzir um jornal para um público que se considerava não consumir O Globo: as classes C e D (SILVA, 2012). Provavelmente em função de o Extra ter crescido mais na classe B, a empresa lançou, em 2006, um jornal mais voltado para as classes C e D, o Expresso (SILVA, 2012).

O Grupo Globo tem um documento de "Princípios editoriais" disponível na internet. ${ }^{6}$ A orientação do documento é de que as opiniões expressas pelos diferentes veículos do grupo sejam comuns: "Os textos podem e devem divergir no estilo, no enfoque, na ênfase nesse ou naquele argumento, mas a essência é a mesma”.

Em sua apresentação no site da Infoglobo, o Extra se intitula "O jornal mais lido do Brasil" e O Globo se considera "O jornal preferido dos formadores de opinião”. Há públicos distintos para ambos, especificados a partir de um recorte de classe social e de escolaridade. Enquanto $\mathrm{O}$ Globo caracteriza seu público como das classes B (50\%), C (28\%), A (15\%) e DE (6\%), Extra apresenta a seguinte configuração de classe:

6 Disponível em: http://gl.globo.com/principios-editoriais-do-grupo-globo.

html\#principios-editoriais. 
C (58\%), B (25\%), DE (15\%), e A (2\%). Em termos de escolaridade, 56\% dos leitores do Extra têm ensino médio, 21\% fundamental e 17\% superior. Já entre leitores d’O Globo predomina o nível superior (39\%), seguido de ensino nédio (22\%) e fundamental (14\%).

Embora a essas diferenças de direcionamento correspondam diferentes estratégias narrativas para configurar os acontecimentos, no caso do Extra, parecem corresponder não apenas a estratégias mercadológicas no sentido estrito de agradar o leitor. Em julho de 2015, mesmo ano do caso da Lagoa, o Extra publicou uma capa que lhe rendeu o prêmio ExxonMobil (antigo Prêmio Esso) de Jornalismo na categoria "Primeira página”. A matéria, intitulada "Do tronco ao poste", aborda a morte de um jovem de São Luís, no Maranhão, que, amarrado a um poste, foi linchado depois de tentar roubar um bar. O Extra comparava a foto da cena a uma pintura de Debret do século XIX que retratava um escravo sendo açoitado em praça pública. O relato descrevia a vítima, de 29 anos, como negro, jovem e favelado. "Se em 1815 a multidão assistia, impotente, à barbárie, em 2015 a maciça maioria aplaude a selvageria. Literalmente - como no subúrbio de São Luís - ou pela internet. Dos 1.817 comentários no Facebook do Extra, 71\% apoiaram os feitores contemporâneos" (Extra, 8 jul. 2015, p. 1).

A abordagem do crime na Lagoa também teve repercussão negativa nos comentários do Facebook. Há de se considerar que nem todo o público que comenta no perfil das mídias sociais do Extra é assinante do jornal. O próprio diretor de redação, Octavio Guedes, afirma que, dos 642 mil fãs que o veículo tinha no Facebook em maio de 2015, apenas 192 mil eram identificados como moradores do Rio de Janeiro (MORETZSOHN, 2015).

O Extra continuou buscando, em anos posteriores, um diferencial na cobertura da violência urbana. No dia 16 de agosto de 2017, anunciava a criação de uma editoria de guerra. A inserção da editoria é explicada não como "uma simples mudança na forma de escrever, mas, principalmente, no jeito de olhar, interpretar e contar o que está acontecendo ao nosso redor" (Extra, 16 ago. 2017, p. 1). 
Podemos inferir que a trajetória do Extra nesse e em outros casos similares pode estar relacionada à necessidade de se diferenciar no mercado, pela intenção de fazer um jornalismo diferenciado e/ou buscar a identificação com o público mais popular (público leitor majoritário da classe C com menor escolaridade), que enxerga a violência urbana de maneira diferente. Uma hipótese possível é a de que o jornal, um pouco mais popular, se abre a modos de endereçamento mais diversos no sentido de captar o público também pela identificação ou piedade para com o criminoso. A construção dos personagens permite que o leitor se sinta vítima também de um sistema ou estrutura social que, em algum momento, também pode deixá-lo em situação de vulnerabilidade social. O Extra não chega a narrar o crime do ponto de vista do agressor, mas se abre a dispositivos argumentativos múltiplos.

Sistematizamos essas características a seguir:

Quadro l - O criminoso, a vítima e o leitor em O Globo e Extra.

\begin{tabular}{lll}
\hline Jornal & O Globo & Extra \\
\hline O criminoso & O criminoso é incompreensível & $\begin{array}{l}\text { O criminoso é vítima da estrutu- } \\
\text { ra social }\end{array}$ \\
A vítima & $\begin{array}{l}\text { Realce da inocência da vítima e } \\
\text { evidenciação dos detalhes de sua } \\
\text { história individual }\end{array}$ & A vítima real é despersonalizada \\
O leitor & $\begin{array}{l}\text { O leitor é convocado como víti- } \\
\text { ma virtual (alteridade pelo risco) }\end{array}$ & $\begin{array}{l}\text { O leitor é convocado em sua } \\
\text { piedade (alteridade pela exclusão } \\
\text { social) }\end{array}$ \\
\hline
\end{tabular}

Fonte: elaboração própria.

Na cobertura analisada, percebemos dois movimentos de configuração do acontecimento: um que, num primeiro momento, acrescenta vítimas à tragédia, relacionando casos distintos para afirmar que adolescentes que vivem na favela não são apenas causadores de violência, mas também vítimas dela, e, num segundo momento, se volta para o passado, especialmente um passado de injustiças e abandono na vida do adolescente que cometerá o ato que se torna o acontecimento jornalístico em questão; e outro que projeta mais o futuro e as medidas que 
devem ser adotadas para evitar outros crimes como esse. Quando busca explicações para o crime, nesse caso, o retorno não é ao passado, mas a uma construção de bandidos que não dão valor à vida, psicopatas. $\mathrm{O}$ próprio conceito de vítima virtual é baseado num suposto futuro em que outros virão a sofrer como a primeira vítima.

Vaz e colaboradores (2006) afirmam que o endereçamento à classe média na política da vítima virtual passa pela descontextualização: "Ser Vítima Virtual não implica nenhuma responsabilidade pelo sofrimento do outro. A identificação individual de um indivíduo com a vítima é um mero desencadeador das preocupações com o seu futuro e o de seus próximos" (VAZ et al., 2006, p. 125).

Por outro lado, os autores reclamam um jornalismo que reconecte a demanda por segurança ao contexto social. Para isso, afirmam, não é preciso reeditar a política de piedade: "Bastaria um sentido mínimo de igualdade perante a lei ou mesmo perante a possibilidade de ser vítima” (VAZ et al., 2006, p. 126), destacando que dificilmente os moradores da favela, que são as principais vítimas da violência, aparecem como tal nos noticiários.

A diferente construção da vítima e do agressor nos jornais analisados nos mostra que esse é um tema que só pode ser tratado tendo em vista um jogo de espelhos em que há estratégias argumentativas específicas. Ora o leitor deve se identificar com a vítima, ora deve se identificar também com a situação social do agressor. As narrativas jornalísticas se configuram, dessa maneira, como dispositivos argumentativos (MOTTA, 2005, 2013) que se utilizam, entre outros recursos, de personagens para criar uma identificação com seus leitores a partir de projetos diferentes no mercado jornalístico.

Assim, são dois projetos dramáticos diferente que instituem o crime, seus personagens e também posicionam os leitores em formas diferentes de experimentação da realidade. No caso analisado, as políticas da piedade e da vítima virtual não são etapas históricas da cobertura de violência, mas formas que convivem numa mesma temporalidade. Uma configura a alteridade no risco e a outra, na pobreza, como apontam os 
autores que inspiraram este trabalho (VAZ, CARVALHO e POMBO, 2006, p. 117).

\section{Referências}

ADEUS, doutor. O Globo, Rio de Janeiro, p. 8, 21 maio 2015.

A ESCALADA da crueldade. O Globo, Rio de Janeiro, p. 8, 22 maio 2015.

ARENDT, H. Da revolução. São Paulo: Ática, 1988.

BICICLETA por uma vida. Extra, Rio de Janeiro, p. 12, 21 maio 2015.

BOLTANSKI, L. Distant suffering: morality, media and politics. Cambridge: Cambridge University Press, 2004.

DO TRONCO ao poste. Extra, Rio de Janeiro, p. 1, 8 jul. 2015.

DUAS TRAGÉDIAS antes da tragédia. Extra, Rio de Janeiro, p. 1, 22 maio 2015.

FREQUENTADORES mudam rotina para driblar assaltos. O Globo, Rio de Janeiro, p. 11, 21 maio 2015.

INDIGNAÇÃO em toda a cidade e nas redes sociais. O Globo, Rio de Janeiro, p. 10, 21 maio 2015.

ISSO não é normal. Extra, Rio de Janeiro, p. 1, 16 ago. 2017.

MORETZSOHN, Sylvia Debossan. 'Jornalismo não é concurso de miss simpatia'. Entrevista com Octavio Guedes. Observatório da Imprensa, 26 maio 2015. Disponível em: http://observatoriodaimprensa.com.br/imprensa-em-questao/jornalismo-nao-e-concurso-de-miss-simpatia/. Acesso em: jun. 2016.

MOTTA, L. G. A análise pragmática da narrativa jornalística. In: CONGRESSO BRASILEIRO DE CIÊNCIAS DA COMUNICAÇÃO, 28, 2005, Rio de Janeiro. Anais... Manaus: Intercom, 2005. Disponível em: http://www.intercom.org.br/papers/nacionais/2005/resumos/R2419-1.pdf. Acesso em: dez. 2017.

Análise crítica da narrativa. Brasília: Universidade de Brasília, 2013.

NA REGIÃO número de jovens detidos é maior que o de adultos. O Globo, Rio de Janeiro, p. 14, 22 maio 2015.

NUNES, M. Eles só querem justiça. Extra, Rio de Janeiro, p. 13, 21 maio 2015.

RECONHECIDO e preso. Extra, Rio de Janeiro, p. 4, 22 maio 2015.

REVOLTA marca enterro no Caju de cardiologista assassinado. O Globo, Rio de Janeiro, p. 10, 22 maio 2015.

SILVA, T. R. N. H1N1 e produção de sentidos na mídia: a epidemia de 2009 nas páginas de O Globo, Extra e Expresso. 2012. 148f. Dissertação (mestrado em Ciências) - Fundação Oswaldo Cruz, Rio de Janeiro, 2012.

TRAGÉDIA ANUNCIADA a 10 quilômetros da Lagoa. Extra, Rio de Janeiro, p. 3, 22 maio 2015. 
VAZ, P. A compaixão, moderna e atual. In: FREIRE FILHO, J.; COELHO, M. G. P. (Orgs.). Jornalismo, cultura e sociedade: visões do Brasil contemporâneo. Porto Alegre: Sulina, 2014. p. 73-96.

VAZ, P.; CARDOSO, J. M.; FELIX, C. B. Risco, sofrimento e Vítima Virtual: a política do medo nas narrativas jornalísticas contemporâneas. Contracampo, Niterói, n. 25, p. 24-42, dez. 2012.

VAZ, P.; CARVALHO, C. S.; POMBO, M. F. A Vítima Virtual e sua alteridade: a imagem do criminoso no noticiário de crime. Revista Famecos, Porto Alegre, v. 30, p. 71-80, 2006.

. Risco e sofrimento evitável: a imagem da polícia no noticiário de crime. Revista da Associação Nacional dos Programas de Pós-Graduação em Comunicação, Brasília, v. 4, p. 2-22, 2005.

VAZ, P. et al. Pobreza e risco: a imagem da favela no noticiário de crime. In: LEMOS, A.; BERGER, C.; BARBOSA, M. (Orgs.). Livro da Compós 2005: narrativas midiáticas contemporâneas. Porto Alegre: Sulina, 2006. p. 111-127.

VAZ, P. et al. Pobreza e risco: a imagem da favela no noticiário do crime. Revista Fronteiras, São Leopoldo, v. 7, n. 2, p. 95-103, 2005.

VAZ, P.; RONY, G. Políticas do sofrimento e as narrativas midiáticas de catástrofes naturais. Revista Famecos, Porto Alegre, v. 18, p. 218-234, 2011.

\section{Sobre as autoras}

Márcia Franz Amaral - Professora do Programa de Pós-graduação em Comunicação da Universidade Federal de Santa Maria (UFSM), doutora em Comunicação e Informação pela Universidade Federal do Rio Grande do Sul (UFRGS), pesquisadora do Conselho Nacional de Desenvolvimento Científico e Tecnológico (CNPq).

Lara Nasi - Professora do curso de Jornalismo daUniversidade Regional do Noroeste do Estado do Rio Grande do Sul (Unijuí), doutoranda no Programa de Pós-graduação em Comunicação da UFSM.

Data de submissão: 20/02/2018

Data de aceite: 24/04/2018 